\title{
An attempt at assessing the economic component of strategic threats to energy security
}

\author{
Dmitrii Kononov* \\ * Melentiev Energy Systems Institute, SB RAS, Irkutsk, Russia
}

\begin{abstract}
The paper studies the main economic threats to energy security and the indicators descriptive of them. Available models to estimate the numerical values of these threats are presented. The results of modeled calculations are provided.
\end{abstract}

Keywords: energy security, strategic threats, indicators, risks.

The International Energy Agency defines energy security as "the uninterrupted availability of energy sources at an affordable price" [1]. This interpretation attests to the important role of the economic component of energy security and the consideration of such strategic threats as the shortage of production capacity in the energy sector and the dynamics of energy prices that are unacceptable for the country's economy. The quantitative assessment of the significance of these threats, the probability of their occurrence, and possible damages is an essential and challenging problem, and there are no satisfactory and generally accepted methods for solving it [2-6].

The threat of possible long-term capacity shortage may be caused by lack of investment and other resources for timely implementation of large-scale projects, issues with the required development in linked industries and infrastructure, and time constraints (inertia).

Investment risks of projects and options for the development of the electric power industry and the share of power plants with unacceptable risk in the mix of new capacity additions can be used as indicators of energy security. For their numerical evaluation, in studies conducted at the SEI SB RAS the MISS-EL stochastic model (computer program) that integrates optimization with the well-established Monte Carlo method is employed [7]. It allows identifying rational options for the development of regional electric power supply systems based on the criterion of minimum discounted cost required to meet the predefined demand for the electric power.

An important feature of the MISS-EL model is that all key input data and constraints are specified not as point estimates but as ranges of possible values, with the ability to factor in the different probability laws that govern the distribution of values within such intervals. The model makes it possible to obtain hundreds of balanced and optimal options under different input data, to select the most stable of them, and to estimate the probability of newly built and reconstructed power plants of various capacity that are getting included into this main option. The lower the probability, the higher

\footnotetext{
e-mail: stranger72@bk.ru
}

the risk to the investor. Accordingly, the investment risk is defined as an inverse value of the probability.

The presented results of calculations performed with the MISS-EL model refer to the option of electric power supply of 6 federal districts of the European part of Russia, including the Ural federal district. The conditions defining this option are similar to those of the minimum capacity option in the General Scheme (Master plan) of new power plant capacity additions until 2035, adopted by the Government of the Russian Federation in June 2017 [8].

The investment risks, as well as the cost of electricity generation, are significantly affected by the projected demand for electricity (Figure 1). This effect manifests itself differently for different plants and depends on the magnitude and nature of uncertainty of the input data (Table 1).

Table 1. Investment risks of new power plants and their dependence on changes in projected electricity demand, $\%$

\begin{tabular}{|l|c|c|c|}
\hline \multirow{2}{*}{ Power plants } & \multicolumn{3}{|c|}{$\begin{array}{c}\text { Deviation from the reference } \\
\text { case }\end{array}$} \\
\cline { 2 - 4 } & $\mathbf{- 5 \%}$ & $\mathbf{0 \%}$ & $\mathbf{5 \%}$ \\
\hline $\begin{array}{l}\text { Steam-electric pow- } \\
\text { er plant, gas-fired }\end{array}$ & $14-21$ & $13-20$ & $11-18$ \\
\hline $\begin{array}{l}\text { Central heating and } \\
\text { power plants, gas- } \\
\text { fired }\end{array}$ & $2-4$ & $1,5-4$ & $1-2$ \\
\hline $\begin{array}{l}\text { Central heating and } \\
\text { power plants, coal- } \\
\text { fired }\end{array}$ & $17-31$ & $4-23$ & $2-18$ \\
\hline $\begin{array}{l}\text { Nuclear power } \\
\text { plants }\end{array}$ & $25-35$ & $19-26$ & $9-17$ \\
\hline Hydropower plants & $16-20$ & $14-17$ & $11-14$ \\
\hline Renewables & $20-40$ & $12-32$ & $11-22$ \\
\hline Average risk value & $12-20$ & $8-17$ & $6-13$ \\
\hline
\end{tabular}

Note. The lower bound was arrived at when assuming the normal probability distribution of the input data, the upper one corresponds to the interval uncertainty.

The modeled calculations demonstrated noticeable regional differences in probability (risks) of the power plant capacity shortage (Table 2).

The table shows that under minimum uncertainty of input data (normal distribution of their probability) the 
weighted average risk of total new capacity additions for power plants in some regions ranges from 4 to $15 \%$, while in the case of interval uncertainty it is 10 to $20 \%$.
In this case, the risk of investing in the construction of individual plants may exceed $50 \%$.
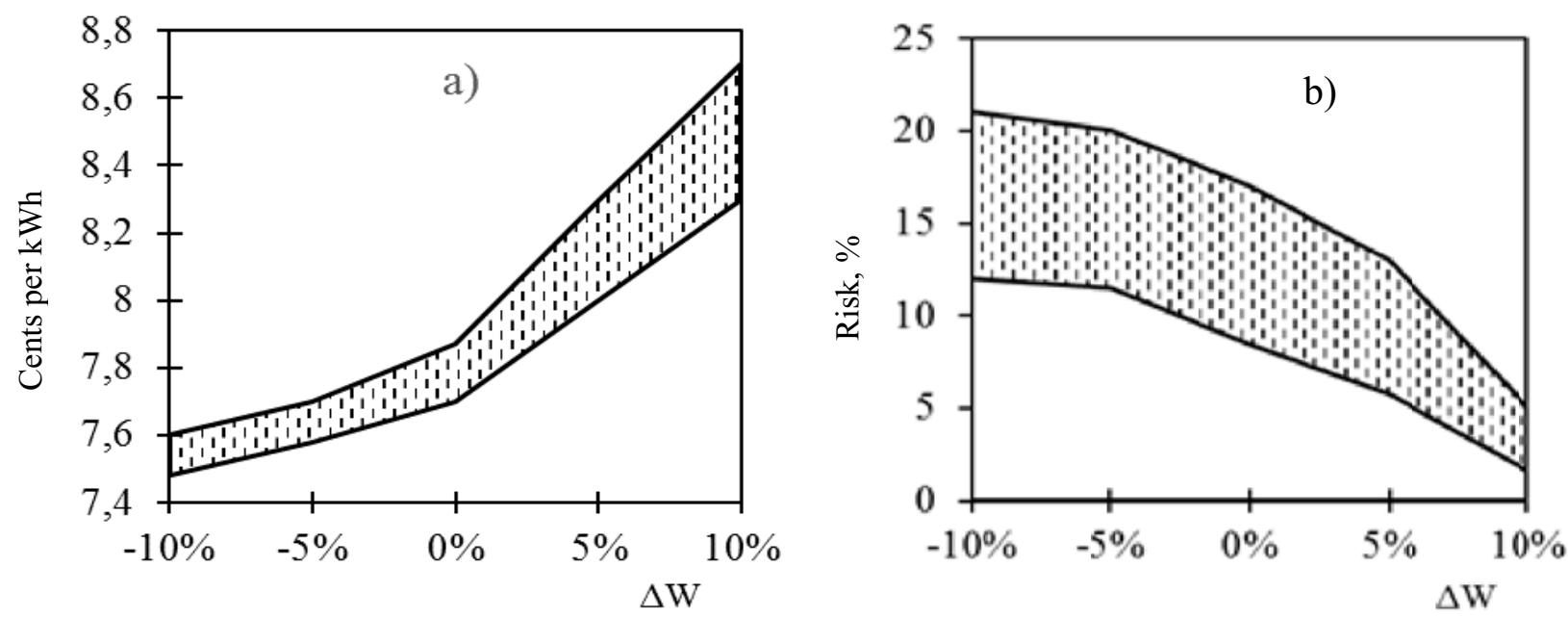

Figure 1. Effect of changes in electricity demand on the average generation cost (a) and risk for investors (b) Note. The lower bound was arrived at when assuming the normal probability distribution of the input data, the upper one corresponds to the interval uncertainty.

Table 2. Effect of the nature of uncertainty of the input data on investment risks and electricity cost in some of the regions (Federal districts)

\begin{tabular}{|c|c|c|c|c|c|c|c|c|}
\hline \multirow[t]{2}{*}{ Indicator } & \multirow{2}{*}{$\begin{array}{c}\text { Unit of } \\
\text { measurement }\end{array}$} & \multirow{2}{*}{$\begin{array}{c}\text { Nature } \\
\text { of uncertainty }\end{array}$} & \multicolumn{6}{|c|}{ Regions } \\
\hline & & & 1 & 2 & 3 & 4 & 5 & 6 \\
\hline \multirow{2}{*}{$\begin{array}{l}\text { Investment risks of power } \\
\text { supply options }\end{array}$} & \multirow[t]{2}{*}{$\%$} & Normal distribution & 9 & 15 & 15 & 2.5 & 4 & 7 \\
\hline & & Interval uncertainty & 19.5 & 20 & 19.5 & 10 & 12 & 17 \\
\hline \multirow{2}{*}{$\begin{array}{l}\text { Percentage of capacity of } \\
\text { plants with the risk of more } \\
\text { than } 50 \%\end{array}$} & \multirow[t]{2}{*}{$\%$} & Normal distribution & 2.5 & 2.2 & 3 & 1.2 & 0 & 7.3 \\
\hline & & Interval uncertainty & 6.5 & 9.3 & 5.5 & 0 & 0 & 6 \\
\hline \multirow[t]{2}{*}{ Electricity cost } & \multirow{2}{*}{$\begin{array}{l}\text { Cents per } \\
\mathrm{kWh}\end{array}$} & Normal distribution & 7.3 & 7.7 & 7.8 & 8.1 & 7.7 & 7 \\
\hline & & Interval uncertainty & 7.3 & 8 & 8 & 8.6 & 8.3 & 7.3 \\
\hline
\end{tabular}

The mix of new power plant capacity additions also depends on the uncertainty of specified conditions. This is evidenced, for example, by the share of HPPs and renewables in the mix of new power plants (Table $3)$. It changes markedly not only if compared to the deterministic option, but also when comparing options with different types of uncertainty. At the same time, due to the specified constraints on new capacity additions in some regions, the change in the uncertainty of the input data leads to an increase in the role of these power plants, while in others - to its decrease.

Modeled calculations provide evidence for a noticeable effect of the discount rate assumed during op- timization on the mix of new capacity additions and, accordingly, on investment risks (Figure 2).

For a comprehensive assessment of the capacity shortage threat in the implementation of an electric power sector development option, it is required to know not only the probability (risk) and magnitude of the shortage, but also the possible macroeconomic damage it does. The cross-sector optimization model MIDL is used to determine it [9]. It follows from the modeled calculations that with an annual one-percent capacity shortage of power plants, the GDP decrease may exceed 0.15 percent.

Table 3. The share of hydroelectric and renewable-energy power plants in the overall makeup of newly built power plants as a function of the way the conditions of the development of regional energy supply systems are handled, \%

\begin{tabular}{|l|c|c|c|c|c|c|c|}
\hline \multirow{2}{*}{ Input data specification } & \multicolumn{9}{c|}{ Regions } & \multirow{2}{*}{$\begin{array}{c}\text { Aggregated re- } \\
\text { gion as a whole }\end{array}$} \\
\cline { 2 - 8 } & $\mathbf{1}$ & $\mathbf{2}$ & $\mathbf{3}$ & $\mathbf{4}$ & $\mathbf{5}$ & $\mathbf{6}$ & 6.9 \\
\hline Deterministic & 1.7 & 11.3 & 0.7 & 11 & 16.9 & 7.3 & 7.1 \\
\hline Normal probability distribution & 1.2 & 11.1 & 2.1 & 12.9 & 16.5 & 7.4 & 7.5 \\
\hline Interval uncertainty & 1.2 & 10.7 & 3 & 10.5 & 15.8 & 11.5 & \\
\hline
\end{tabular}




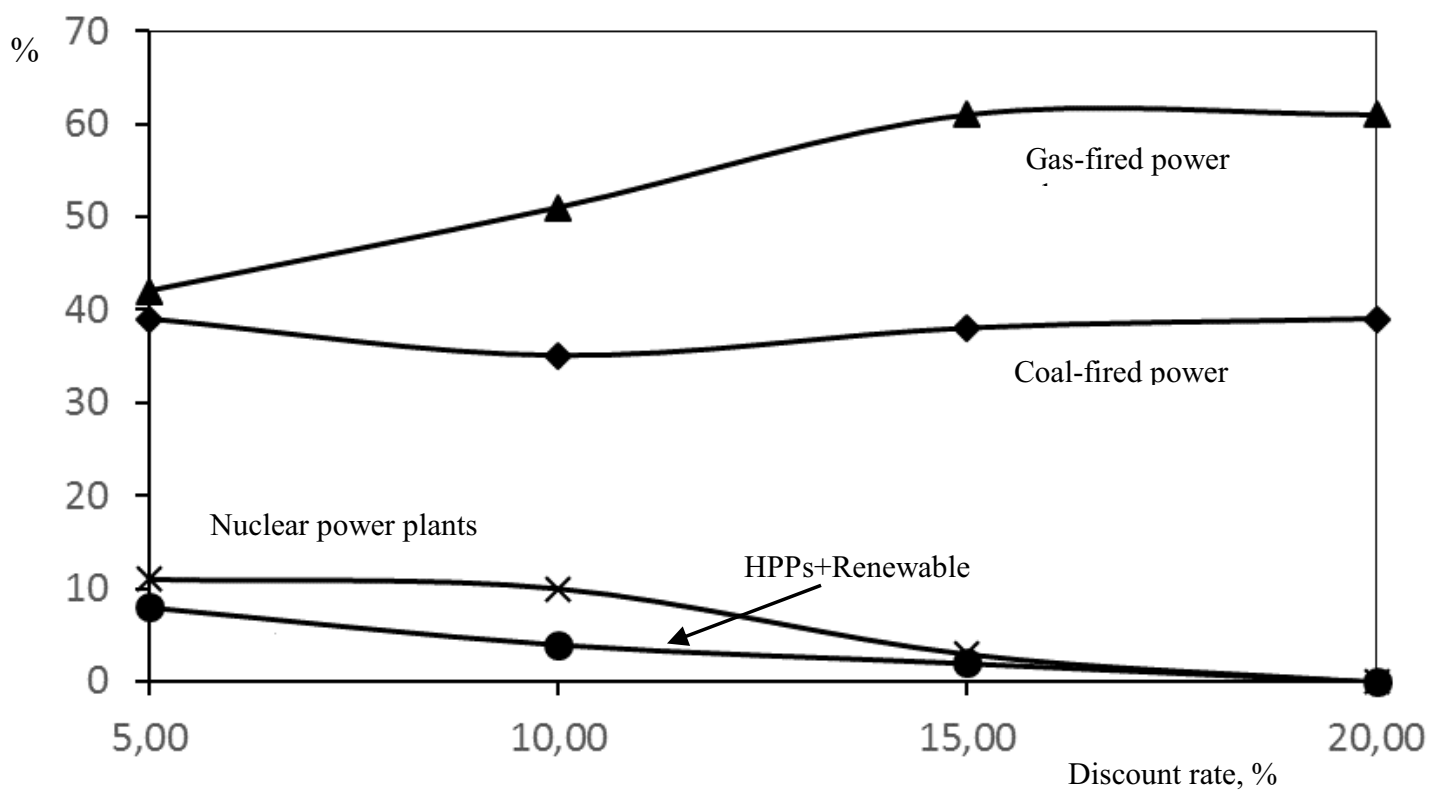

Fig. 2. The effect of the discount rate on the mix of new power plant additions

The reasons for the threat of unacceptable dynamics of an electricity price increase may be any of the following: contradictions between the interests of producers and consumers, uncertainty of the market state, slower improvement in living standards, low adaptability of consumers to price changes, or high energy intensity of the economy. Among the most important energy security indicators characterizing this threat one can highlight the following ones:

1. Price elasticity of demand for electricity.

The higher the price elasticity of demand for electricity, the higher the level of consumers' adaptation to the threat of its rise in price.

2. Share of electricity costs in the GDP

This share in Russia is now about $11 \%$, which is $2-$ 3 percentage points higher than the world average. However, it could increase significantly with the implementation of the Paris Agreement to reduce CO2 emissions.

3. Decrease in the GDP growth rates given increased electricity price

The latter indicator, which characterizes the negative response of macroeconomic indicators to increased electricity price can serve as an overall characteristic of the price threat to energy security. For the purposes of its approximate numerical estimation, it is possible to use the system of models developed at the SEI SB RAS (Figure 3), the main role in which is played by the cross-sector optimization MIDL model, as well as models that assess the impact of increased prices of energy carriers on prices in the production sector and on reducing final consumption of goods and services in the tertiary sector. An example of such assessment is given in Table 4.

The results of modeled calculations show that depending on the structure and pace of economic development and other factors, the price elasticity of the GDP with respect to the price of electricity may vary in the medium term from -0.12 to $-0.16 \%$. In the long run, the impact of electricity cost changes on economic growth should diminish.

Among the unsolved problems of numerical evaluation of strategic threats to energy security, one can highlight the problem of constructing a composite (overall) index of these threats that would take into account their interrelationships and relative significance of these threats as it changes over time.

Table 4. Changes in macroeconomic performance indicators given an increase in the electricity price, $\%$

\begin{tabular}{|c|c|c|c|c|c|c|}
\hline \multirow{3}{*}{ Performance indicators } & \multicolumn{6}{|c|}{ Growth in electricity tariffs } \\
\hline & \multicolumn{2}{|c|}{ by $20 \%$} & \multicolumn{2}{|c|}{ by $50 \%$} & \multicolumn{2}{|c|}{ by $100 \%$} \\
\hline & Year 2010 & Year 2030 & Year 2010 & Year 2030 & Year 2010 & Year 2030 \\
\hline Inflation rate & 0.7 & 0.3 & 2.2 & 0.95 & 4.8 & 2.3 \\
\hline Cost of living & 0.8 & 0.7 & 2.4 & 1.9 & 5.2 & 4.2 \\
\hline GDP & -2.0 & -1.6 & -3.6 & -3.1 & -6.3 & -5.5 \\
\hline $\begin{array}{l}\text { Final consumption of goods and } \\
\text { services }\end{array}$ & -2.4 & -1.6 & -4.5 & -3.2 & -8.1 & -5.9 \\
\hline
\end{tabular}




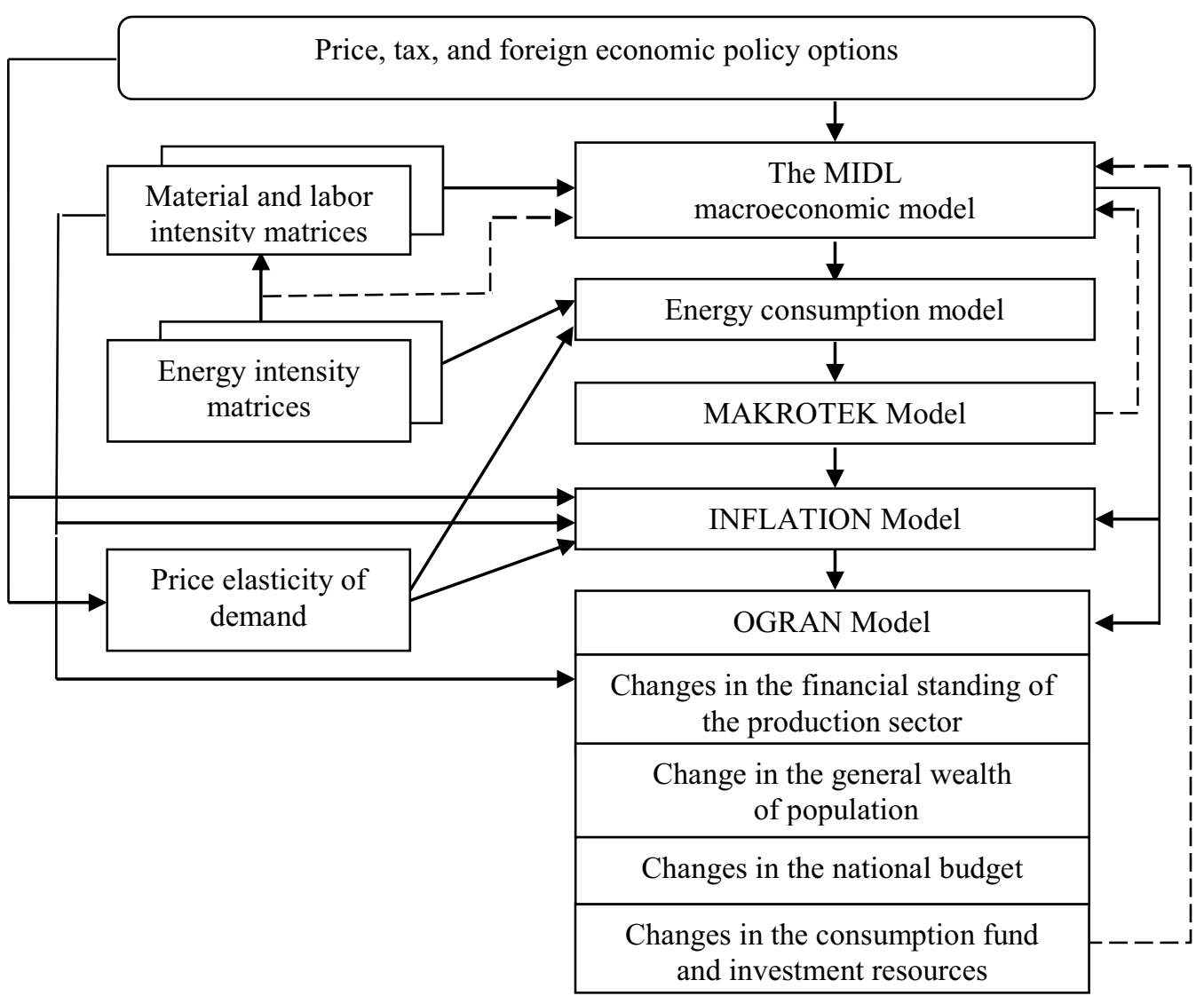

Figure 3. The MESTEK model system

The research was carried out under State Assignment III.17.5.2 (reg. No. AAAA-A17-117030310432-7) of the program for basic research of the SB RAS, the research was supported in part by an RFBR grant under the research project No. 20-010-00204)

\section{References}

1. IEA. Measuring short-term energy security, $15 \mathrm{p}$. URL:

http:www.yumpu.com/en/document/view/1962105 6/measuring-short-term-energy-security-iea (2011)

2. Kononov Yu.D. Analysis of the experience accumulated abroad in the comprehensive assessment of energy security // Energeticheskaya politika, № 6, pp. 98-107. (2018) (in Russian)

3. Senderov S.M., Rabchuk V.I., Pyatkova N.I. Ensuring Russia's energy security: setting priorities. Novosibirsk: Nauka, 116 p. (2017) (In Russian)

4. Handbook on Constructing Composite Indicators: methodology and user guide / OESD, 152 p. (2018)

5. Energy Security: a review of studies of the economic value of energy security // Universita degli studi di Padova, Anno Accademico, 110 p. (2015/2016)

6. Augutis J., Krikstolatis R., Martisauskas J. Integrated Energy Security Assessment // Energy, № 128, pp. 890-901. (2017)

7. Yu. D. Kononov, V. N. Tyrtyshny, D. Yu. Kononov. The application of stochastic modeling in chooing regional energy supply options while addressing investment risks // Informacionnye $i$ ma- tematicheskie tekhnologii v nauke i upravlenii, № $\mathbf{2}$, pp. 80-87. (2018) (In Russian)

8. Ermakov S.M. The Monte Carlo method and related issues. M.: Nauka, 472 p. (1975) (In Russian)

9. The General scheme of placing of objects of electric power industry until 2035. Government of the Russian Federation. No 1209-p http://static.government.ru/media/files/zzvuuhfq2f3 OJIK8AzKVsXrGIbW8ENGp.pdf (2017) (In Russian)

10. Yu. D. Kononov, E. V. Galperova, D. Yu. Kononov et al. Methods and models for projections of the energy-economy interactions. Novosibirsk: Nauka, 178 p. (2009) (In Russian) 